\title{
Exploring Ways to Make Generation Z like Classical Music Better
}

\author{
Yihang $\mathrm{Xu}^{*}$ \\ Donovan Catholic High School, 711 Hooper Ave, Toms River, NJ, 08753, United States \\ ${ }^{*}$ Corresponding author.Email: guanghua.ren@gecacademy.cn
}

\begin{abstract}
As the most complicated music, classical music contains a large group of audiences. However, some studies show that nowadays, classical music audiences are gradually declining. Hence, the research explores how to make generation $\mathrm{Z}$ like classical music better and gives numerous suggestions to make it more popular. The mythology used in this research is a qualitative research method, in-person, in-depth interview (IDIs), plus an interactive experiment. All interview results will be categorized into two main units: people's background information about classical music and why people like, dislike or hate it. The experiment outcome will be listed separately. The interview results illustrate that less than half of Generation $\mathrm{Z}$ like classical music. They also do not have correct knowledge of classical music. Although many of they have learned classical instruments, only a few of them liked it because of learning it. Apart from that, the results also indicate the reason why Generation $\mathrm{Z}$ likes classical music: the atmosphere, beauty created by it, and the culture behind this music. On the contrary, they don't like classical music is because it's not modern and fashionable enough; they have been forced to learn classical instruments and their serious stereotype. The experimental results illustrate the audience's attitude towards music recommendation: they like friendly and non-mandatory recommendation methods and songs like their original favorite songs. Therefore, classical music promoters can eliminate the estrangement with unfamiliar listeners in the future, and then give full play to their advantages and integrate with the preferences of generation $\mathrm{Z}$, finally attracting a new audience.
\end{abstract}

Keywords: Music, Classical music, music styles, Interests, Music recommend, Generation Z.

\section{INTRODUCTION}

In essence, Music is "the art of arranging sounds in time through the elements of melody, harmony, rhythm, and timbre [1]", when people listen to music, they can shake off all their problems, let their imagination out of bondage, lost in those beautiful melodies and rhythms. And among all music types, classical music is one of the most complex music in the world. Classical music is a "Music mainly centered on Franz Joseph Haydn, Wolfgang Amadeus Mozart, and Ludwig van Beethoven in the late 18th and early 19th centuries, as well as a considerable number of compositions composed after 1900 [2]", and it's known for its "complexity in the use of orchestration, counterpoint, harmony, music development, rhythm, wording, texture, and form, and besides from its complexity [3]", and it possesses hundreds of years of history. At first, only the royal nobles in Europe could enjoy this kind of music, but today, we can all enjoy it whether on our phones or in the theater.
However, in the global economic depression environment, the state of the classical music industry is getting worse, many classical music performing institutions have broken. According to multiple reporters' interviews of several classical musicians, they got shocking news: classical music is gradual declining, making a profit by it is getting hard and hard, this musician and his colleagues can only play music reluctantly with the government's help and donations from the outside world due to the classical music's listener still declining. Musician Dawn Bennett points out, "musicians in the twenty-first century require a broad and rapidly evolving suite of skills on which to build and sustain their careers [4]." Today's classical musicians need more than just to be able to play an instrument proficiently to survive in the industry. They also need to learn how to attract an audience, build awareness online, and not lose out to other kinds of music, but their prospects remain grim. 
There is a very extreme example of this situation: "During the epidemic, classical musician Liang Yi Zhang and his IJ space chamber orchestra were unable to perform offline, so they contacted the online live broadcast for the first time. Although IJ space cooperated with chakong ancient music and only received a reward of 162 yuan (about 25 US dollars) for the online concert broadcast by Wangyiyun cloud music, many unknown network anchors received more than this in an hour [5]". Another report also mentioned this situation with intuitive figures, which shows that in 2012, "classical album sales declined by 21 percent. In the following year, only 2.8 percent of albums sold in the U.S. were classical. This is a stark contrast to other genres, such as rock, which consisted of 35 percent, and R\&B, which consisted of 18 percent [6]". These words undoubtedly sound frustrating, but how did this music with such a long history get to where it is now? And is can this situation be reversed?

To find the answer, young people, also known as the generation Z's, opinions must be heard clearly for they are the future of the modern music industry. Generation $\mathrm{Z}$ spends an average of four hours per day listening to music, and every day, "Gen $\mathrm{Z}$ is bombarded with more knowledge than every other generation before them. Music marketers need to catch their attention quickly before they switch on to somewhere else. Music appears to be the unifying factor for Gen Z [7]". This research aims to explore the methods of making generation $Z$ like classical music better, and this research also gives out useful suggestions for classical musicians themselves. The main body of this paper is divided into two parts: a series of interviews and experiments.

According to the literature review, existing studies on classical music usually use the data of listening to classical music on the music platform and the number of people learning classical music to infer people's attitudes towards classical music. For they do not listen to the real views of the younger generation on classical music, so they are sometimes confused by the cold data representation. However, this research focuses on generation Z's realist feelings about classical music. Therefore, this research also infers the real situation of classical music and aims to fill the gap in the literature review.

\section{METHODS}

This research itself is qualitative research, and since it "relies on data obtained by the researcher from first-hand observation, interviews, questionnaires [8]", mixed methods, which combined Method of an in-person in-depth interview (IDIs) and an interactive experiment is applied.

In-person in-depth interview is "a qualitative research technique that involves conducting intensive individual interviews with a small number of respondents to explore their perspectives on a particular idea [9]", continuous interview questions will be designed based on interviewees' answers, like "which classical song do you like the most?" "Why do you like it these much?" Their answers will help decide which question should be asked next. In the begging, this interview will divide interviewees into two sections. One is those who like classical music. Another one is those who dislike/hate classical music. These questions can be beneficial to find out how many members of Generation $\mathrm{Z}$ love classical music. Also, the data will present why they like or don't like classical music and what other types of music they like.

The interviewees are from different ages, regions, genders, and classes. The random selection of interviewees is to avoid the influence of similar backgrounds factors and other conditions. Also, the research would not include any close relationship people with interviewers because familiars easily accept the final song recommendations.

A little experiment will be added at the end of the interview for those people who dislike/hate classical music to determine the correct way of recommending classical music. This is an interactive experiment. For this study, the introducer will play a classical song to the interviewees and ask them if they like it or not. This can testify to people's communication potential in the experiment. The introducer can control two variables: one is his own attitude, another is the song that he plays for interviewees, song selections.

For attitudes, the introducer has two options. One is the cold attitude: In the process of recommending songs, the introducer will directly play random classical music to the interviewer and ask the interviewer whether he likes the song without any emotion. The other one is the friendly character: Before starting the experiment, the introducer will create a good and enthusiastic chat environment during the interview, vividly introduce the relevant knowledge of classical music to the respondents, understand and remember their favorite music types, and explain the story behind the song during the playback.

In terms of song selection, the introducer also has two options. One is playing songs randomly: No matter what type of song the interviewees like, the introducer will only play the one fixed song for them; another one is play songs carefully selected according to his respondents' preferences: Since during the interview, the introducer can ask and understand what types of music the interviewees like, he can continue asking about their favorite song, and then he can choose one classical song that matches with interviewees' favorite song's atmosphere, melody, musical instrument texture, the most, for example, if it is a melancholy folk song, then the interviewer will play the sad opera with the harp the 
main instrument. According to Julian Johnson, "the different potential of musical types arises not just from how people approach different kinds of music but from the objective difference between musical pieces and musical styles themselves [10]," so by reducing the differences between the two types of music, people will be more receptive to music they haven't been exposed to.

Whenever the introducer can only change one variable, he needs to use all kinds of combinations to determine which variable influences the interviewees the most. There are four types of combinations in total. After he finished all kinds of combinations, the data will be collected. If the respondents express their love for the song being played, the experiment will be regarded as a "success". On the other hand, if they do not express their love or directly say that they do not like the song being played, the experiment will be regarded as "failed". In the end, the interviewer will collect all data, summarize which factors will most affect the success rate of recommending classical music to generation $\mathrm{Z}$ and making them like it.

In the end, all the data will be collected for further analysis.

\section{RESULTS \& DISCUSSION}

\subsection{People's background information about classical music}

If people want to like a kind of music, it is essential to understand the basic background knowledge of their music. If people know a kind of music, it will also become an obstacle for them to accept this kind of music.

\subsubsection{The rate that interviewees like, dislike, or} hate classical music

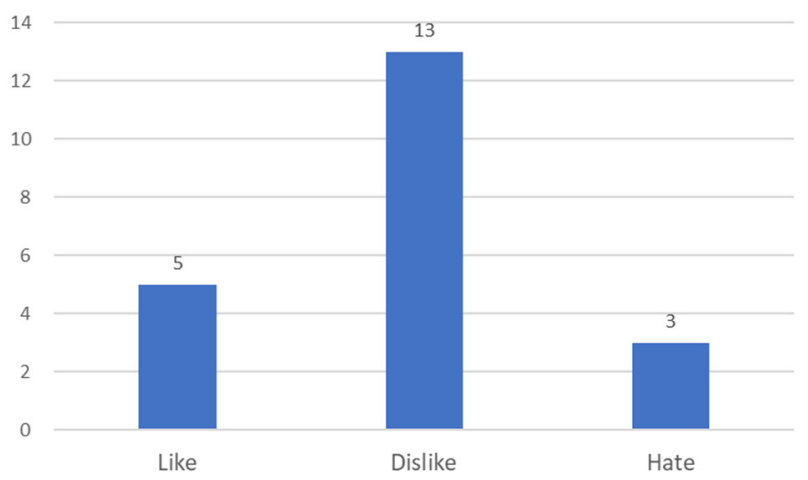

Figure 1 Interviewee's attitudes towards classical music

The first step is to verify how many percent of people like/dislike/hate classical music because these data can present generation z's true attitude towards classical music and help future analysis.
Figure 1 shows the interviewees' attitude about classical music. 21 people have attended the interview. Only 5 people liked classical music in the first place, so it shows that generation $\mathrm{z}$ really doesn't have much interest in classical music. Reasons will be discussed in the next paragraphs.

\subsubsection{The number of interviewees who have knowledge of classical music}

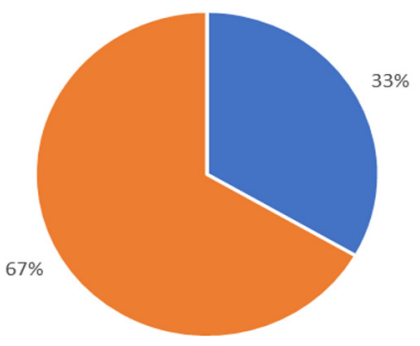

- have knowledge $n$ no knowledge

Figure 2 Interviewee's background information towards classical music

According to Figure 2, two third of the people don't have any knowledge about classical music, and some of them have some serious stereotypes, for like classical music is always 10 minutes long. This kind of lack of information will create a wall between classical music and potential listeners. For instance, one of the interviewees claims that she never listens to classical music specifically because she heard to listen to classical music, people need to learn music theory. She thought it was too complicated, so she gave up on listening.

As mentioned above, learning classical music is trending in gen $\mathrm{z}$ now. Some people hate classical music because they were forced to learn it, but there still could be some people who fell in love with classical music because of it. The interview also calculated the information below to verify if learning classical music can help kids love classical music.

\subsubsection{The number of interviewees who know classical music}

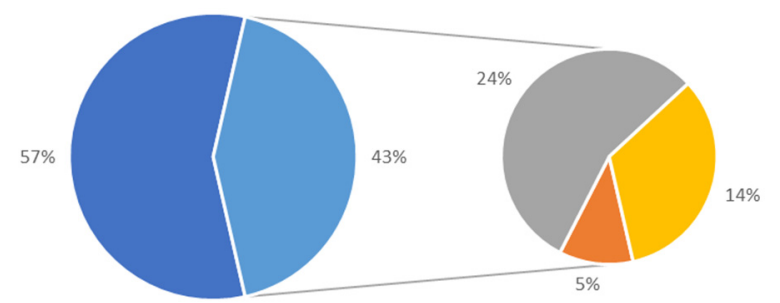

- Never Learned - liked after learned

- Disinterested after learned $=$ Hate after learner

Figure 3 Interviewees with knowledge about the classical instrument 
Figure 3 shows the number of people who have learned classical music. Of those people who learned, only one person liked classical music because of learning it. So yes, forcing kids to learn classical music can't really help. Because forcing kids to learn a type of music that they are not interested in will only make them feel bored, even detest. And the more they learn, the more interest they will lose in classical music. In the end, they may never listen to the music linked to endless boring practice in their hearts.

\subsection{The reason why people like, dislike or hate classical music}

\begin{tabular}{|l|l|}
\hline Like & \multicolumn{1}{|c|}{ Dislike/Hate } \\
\hline Vibe & Old fashion \\
\hline Beauty & Forced learning \\
\hline Culture & Stereotype \\
\hline
\end{tabular}

Figure 4 The reasons why interviewees like/dislike/hate classical music

Figure 4 is the general summary of why people like/dislike/hate classical music. People like it because they feel classical music can provide them with a sense of atmosphere. For example, listening to classical music while doing homework or relaxing for a walk will make people feel very relaxed. Classical music can also provide a sense of elegance when dating a lover in an upscale restaurant.

Some people also think classical music has the most beautiful melody among other music, and the way musicians perform is also beautiful. Some people enjoy classical music culture, such as its history, representatives, phenomena, etc. However, others may dislike classical music because of severe stereotypes such as excessive length, boring, non-lyrics, and appreciation. Additionally, some people believe that classical is old-fashioned, which is lacks modern stuff. Finally, of course, some people hate classical music because they were forced to learn it. One of the interviewees expressed his feeling about classical music with multiple sighs and said classical music bored him because when he was young, his neighbor was always practicing the piano, this noise sometimes even made him angry. Later, when his mother took him to learn piano, he started to hate classical music.

The above is basically the useful information summarized by all the interview questions. Those are all real opinions about classical music from generation $\mathrm{Z}$. Next is the analysis of the data obtained from the experiment, a small simulation of how to correctly introduce classical music to teenagers

\subsection{Experiment outcome}

According to the method described in the second section of this paper, this experiment shows how many people end like classical music after the introducer played a classical song. Below is the outcome of this experiment.

\begin{tabular}{|l|c|c|}
\hline & $\begin{array}{c}\text { Play a same } \\
\text { song }\end{array}$ & $\begin{array}{c}\text { Play selected } \\
\text { songs }\end{array}$ \\
\hline Cold attitude & 1 out of 4 liked & 2 out of 4 liked \\
\hline Friendly attitude & 1 out of 4 liked & 3 out of 4 liked \\
\hline
\end{tabular}

Figure 5 The experiment outcomes

According to Figure 5, people don't like how the introducer forces them to listen to classical music. Still, if the introducer selects songs according to their preference with a friendly way of communication, they will have the most communication potential. For example, three out of four people liked the introducer's songs in the last category.

Additionally, results also indicate that "Friendly attitude" and "selected songs "obviously succeed more time. People don't like how the introducer pushes them to listen to a type of music, they feel uncomfortable about it, so they are less likely to embrace it into their lives. Interviewees do like the way the introducer starts with a normal chatting and just play a classical song that is like their favorite music type with no pushing at all. For example, one interviewee likes to listen to American country music, the introducer played harp music with lyrics into, the interviewee found out the harp is kind of like the guitar, and the vibe doesn't feel much different, in the end, she added this song to her playlist. Moreover, they generally believe that integrating classical music with short videos and modern music will be more interesting.

\section{CONCLUSION}

With the passage of time, many things that once existed and even became popular will disappear, but if a thing has experienced the test of time and still exudes its own charm, this kind of thing is called "classic". As the ancestor of modern music, classical music enjoys a noble position in the music world, exudes its own unique elegance and provides listeners with unparalleled auditory enjoyment. But for many reasons, classical music is losing its access to new audiences, especially among generation $\mathrm{Z}$. If a type of music continues to fail to attract new audiences, the number of its listeners will be less and less, and its treasure of the whole music 
industry will be less and less known, this is a huge loss for the audience and the whole music industry, so it is important to find out why generation $\mathrm{Z}$ generally has little interest in classical music and methods of making generation $\mathrm{Z}$ like classical music better.

Through interviewing and experimenting, we reached out following conclusion. There are still percentages of generation $\mathrm{z}$ who like classical music. However, more generation $\mathrm{Z}$ still has no interest in or even dislike classical music, and here are all the reasons.

Firstly, modern young people generally have little or no understanding of classical music. The survey shows that many people don't know what music classical music contains. Even if they hear good classical music, they don't know it's classical. In the eyes of those who don't like it, classical music is a kind of music that is "boring, too long, difficult to understand, inconvenient to listen to, and inconsistent with modern aesthetics", and it's a heavy stereotype. Secondly, many gen z don't even want to know anything about classical music due to those stereotypes. Even if they do, they don't have enough ways to understand classical music, can't find their favorite style, and then they just give up understanding. Thirdly, too many kids were forced to learn a classical instrument, making them lose their interest in it. Today's parents like to force their children to learn an instrument of classical music, but they don't allow them to enjoy it. According to data from the interviewees, no one likes classical music because he studies classical music. Even if a person does not hate classical music because he is forced to learn musical instruments, this will lead them to flatten their love for classical music in the boring study day after day. Classical music can no longer open their position space. It is difficult to be enthusiastic about it.

On the contrary, all people who like classical music listen to some good classical music or understand the charm of classical music, which stimulates their desire to listen to more good music. They like it because they feel classical music can provide them with a sense of atmosphere. For example, listening to classical music while doing homework or relaxing for a walk will make people feel very relaxed. Classical music can also provide a sense of elegance when dating a lover in an upscale restaurant. Some people also think classical music has the most beautiful melody among all the other music, and the way musicians perform is also beautiful. Some people like the culture of classical music, such as its history, representatives, phenomena caused by it. These people all think that classical music is the most suitable as background music, and they listen to it when learning and thinking. Generation $\mathrm{Z}$ also hopes that they will not be forced to learn classical music and that classical music cannot be so "high above" but can integrate into the group and integrate more with current music. Otherwise, it is difficult for the masses to like art with a too-long history, even if its melody is beautiful.

Therefore, what can people do with the audience? We need to supply their knowledge of classical music interestingly, recommend them some classical music that is very similar to their own favorite music, and let them watch good videos with classical background music to increase their interests. And we can't force them to like or learn it. Moreover, to classical music itself, if classical musicians want to attract more audience, classical musicians have to combine classical with modern music.

\section{REFERENCES}

[1] Wikipedia (2021). Music. [Online] Retrieved September, 14, 2021, from https://en.wikipedia.org/wiki/Music

[2] William Gibbons (2018). Unlimited Replays: Video Games and Classical Music. [Online] Retrieved September, 14, 2021, from https://books.google.com/books?hl=en\&lr=\&id=B6 RTDwAAQBAJ\&oi $=$ fnd\&pg $=$ PT10\&dq $=$ classical + music\&ots $=$ KB8pjLkA_N\&sig=mdqoRZZDQvv $\mathrm{x} 8 \mathrm{cfSq} 8 \mathrm{CKYy} 1 \mathrm{Eve} 8 \# \mathrm{v}=$ onepage $\& \mathrm{q}=$ classical $\% 20$ music \&f $=$ false

[3] Wikipedia (2021). Classical music. [Online] Retrieved September, 14, 2021, from https://en.wikipedia.org/wiki/Classical_music

[4] Dawn Bennett (2016) Understanding the Classical Music Profession: The Past, the Present and Strategies for the Future. [Online] Retrieved September, 14, 2021, from https://books.google.com/books?hl=en\&lr=\&id=u7 YRDYZtFMQC\&oi=fnd\&pg=PP13\&dq=classical + music\&ots=aaqKd_Q6ck\&sig=0fgEeC1Ro_1ZBr RqU9CmdV6Vkcc\#v $=$ onepage $\& q \& \mathrm{f}=$ false

[5] Pan Wen Jie (2021). "It's difficult to make a living. Can live performance make classical musicians make money"? [Online] Retrieved September, 16, 2021,

from https://www.sohu.com/a/388850140_99897611

[6] Phyllis Feng (2019). Is Classical Music on the Decline? [Online] Retrieved September, 19, 2021, from

http://culture.affinitymagazine.us/is-classical-music -on-the-decline/

[7] GEMTRACKS staff (2021). 2021 Trends: How Music Is Marketed to Different Age Groups. [Online] Retrieved September, 23, 2021, from https://www.gemtracks.com/guides/view.php?title= how-music-is-marketed-to-different-age-groups\&id $=676 \#$ gen $-\mathrm{z}$ 
[8] Wikipedia (2021). Qualitative research. [Online] Retrieved September, 23, 2021, from https://en.wikipedia.org/wiki/Qualitative_research

[9] Carolyn Boyce, MA, Evaluation Associate Palena Neale, PhD, Senior Evaluation Associate (2006) CONDUCTING IN-DEPTH INTERVIEWS: A Guide for Designing and Conducting In-Depth Interviews for Evaluation Input. [Online] Retrieved September, 23, 2021, from https://donate.pathfinder.org/site/DocServer/m_e_t ool_series_indepth_interviews.pdf

[10] Julian Johnson (2002). Who Needs Classical Music? Cultural Choice and Musical Value. [Online] Retrieved September, 24, 2021, from https://books.google.com/books?hl=en\&lr=\&id=oP $\mathrm{x} 0$ RyZoOuoC\&oi $=$ fnd \&pg $=\mathrm{PA} 3 \& \mathrm{dq}=$ classical $+\mathrm{m}$ usic\&ots $=$ p7SMMEt-G\&sig=vtE_EvaMDZNJBQ WT6Dtg0eEYZkg\#v $=$ onepage $\& \mathrm{q}=$ classical $\% 20 \mathrm{mu}$ sic\& $\mathrm{f}=$ false 